\title{
Design and Development of Chilli Seeder
}

\author{
Digvijaysinh B Dodiya, Jayesh R Koisha
}

\begin{abstract}
India is the second-largest producer of chilli in the world. The seeds of chilli, capsicum etc. are commonly sown and developed in nurseries using plug tray for better germination. Then grown plants sent to farmland for further cultivation. It was observed that the process of sowing seeds in plug tray require more time because the seed are small and one has to drop it manually. Moreover, this is tedious work and the owner have to pay high for this. So, objective of the study was to evolve a Plug Tray Seeder which were affordable to nursery owners. Which work on pneumatic principle. It was designed in such manner that it has higher seedling rate and less power consumption. In addition, it should also reduce human effort and labour cost. The capacity of seeder, is assumed, depending on the tray size used which range between 27000 and 46800 cell per hour. The total cost of the precision plug seeder is estimated to be ₹17800 (US\$242).
\end{abstract}

\section{INTRODUCTION}

The Agriculture is the one most essential sectors of Indian Economy. Agriculture sector's share in India's Gross Domestic Product (GDP) is of $16 \%$ and provides employment to $50 \%$ of the countries workforce. India is the world's largest exporter, producer and consumer of chillies in the world. Although India is the world leader in chilli production, there is huge scope for improvement in overall efficiency and chilli production. So, if we can improve the process of chilli cultivation with mechanical equipment it would be a huge push for the sector.

In India, mainly chilli cultivation is sown with F1 hybrid seeds, which are expensive but give higher yields and better quality. Because of the higher cost it is, important to achieve higher germination and disease-free seedlings for transplanting in open fields. Upraising seeds in plug trays under controlled environment has accomplished such requirements. Furthermore, this technology has benefitted nursery owners and farmers both. First of all plug tray is filled with a soil-less substrate, consisting of vermiculite and a cockpit, and one by one all seed is manually placed in each cell. In contrast, placing single seeds in cells is the most labour-intensive work. From the experiment it is illustrated that the average human of the seedling is 8000 to 9800 seeds

Revised Manuscript Received on October 25, 2020.

* Correspondence Author

Digvijaysinh B Dodiya*, Graduated Student, Mechanical Department, BVM Engineering College, V.V.Nagar, Anand (Gujarat), India.

Jayesh R Koisha, Assistant Professor, Mechanical Department, BVM Engineering College, V.V.Nagar, Anand (Gujarat), India. Email: jrkoisha@bvmengineering.ac.in

(C) The Authors. Published by Blue Eyes Intelligence Engineering and Sciences Publication (BEIESP). This is an open access article under the CC BY-NC-ND license (http://creativecommons.org/licenses/by-nc-nd/4.0/) per 8 hours. The problem with the manual method is that it is a very tedious and time-consuming task, therefore labour cost is very high. Also in times of high demand, the speed of human labour is not enough and non-availability of labour at effective wage is another issue. Therefore, it is necessary to develop a pneumatic based machine which is operated smanually having higher seedling rate than the tradition method. To make it simple in construction to reduce the cost of manufacturing thus making it affordable for local nurseries as well as farmers.

\section{LITERATURE REVIEW}

Chen (1993) [1] developed a multipurpose vacuum seed planter suitable for vegetable crops whose seed are flat and spherical. It was concluded that the machine was 36 times faster than planting done by hand. Kim (2003) [2] evolved a vacuum nozzle seeder for the sowing of large seeds of vegetables, fruit and rootstocks. They concluded that for obtaining high seedling rate it is essential to control nozzle diameter and vacuum pressure. Hu (2003) [3] created a magnetic precision seeder for plug seedlings, seeds which were coated by magnetic powder. Magnetic field control seed singulation and seeds picked up magnetic head. Gaikwad (2007) [4] developed a pneumatic seeder for nursery plug trays. From Experiments, they concluded efficiency of machine in perspective of singulation, seed utilisation and seeding. Also, relate efficiency with nozzle diameter and suction pressure. Mohamed (2017) [5] developed precision seeder for nursery tray. Carried various experiment and found out perfect nozzle diameter and vacuum pressure for seedling of tomato and cantaloupe-melon seeds. Also, they determine approximate productivity and energy consumption. Moreover, they carried out a cost analysis. Naik (2017) [6] designed an automated seeder for vegetable plantation in plug trays. They calculated the time of their automated seeder and compared with other methods and available machines. Additionally they performed cost and time analysis.

\section{DESIGN}

\section{A. Design Consideration}

The basic considerations in the design of chilli seeder were the cost of the machine, ease of operation, portability moreover using lightweight components along with ergonomics and kinematics. Pneumatic singulation of seed by choosing specific nozzle diameter can be done. Vacuum pump, vibrating motor, solenoid valve, nozzles, pipes and some other electric and mechanical component is supposed to be bought directly.

\section{Published By:}

Blue Eyes Intelligence Engineering and Sciences Publication

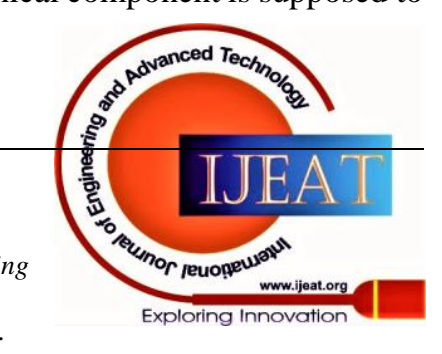




\section{Design and Development of Chilli Seeder}

Other mechanical components were designed and it will be fabricated. As it is semi-automatic it will create convenience to the worker and things will be in a reach of worker that is why from ergonomics perspective tray platform height was decided to keep $855 \mathrm{~mm}$.

Operational Procedure:

a) Taking a plug tray from a side and putting it at a specific place. (2 seconds)

b) At same time Nozzle Assembly is at rest and it is sucking seed.

c) After completion of the first task it will be oscillated manually and it will be moved until stopper comes. There seed will be dropped and it will be moved to position. (4 seconds)

d) Further plug tray will be moved aside. And an empty plug tray will be pulled and the process will repeat. (2 seconds)

The cycle of (a) to (d) is assumed to be complete in $8 \mathrm{sec}$ for a plug tray. This will result into a higher production rate. Modelling and Motion Analysis was carried out in PTC CREO 4.0 to see time synchronization and create drawings for fabrication.

\section{B. Overview of Major Parts}

The seeder consists of several major elements to fulfil the task which is to be designed properly from a mechanical perspective. Those systems were double crank mechanism (DCM), nozzle assembly (NA) and vibrating seed tray (VST). Provisions were made for changing nozzles, suction pressure, seed pickup height and frequency of vibration of the seed tray conveniently.

\section{1) Double Crank Mechanism}

The Machine uses a well-known 4 bar chain mechanism for precise motion of Nozzle assembly to pick seed from seed tray and drop it at the center of respective plugs. Two opposite links are equal in length and parallel. Centre to center distance of link was $120 \mathrm{~mm}$ and distance between to link was $150 \mathrm{~mm}$. It was decided on the base of stability and also reach of the nozzle assembly. Moreover, the inclination of the link on left side was $46^{\circ}$ and on the right side it was $54^{\circ}$. It was decided on the basis of the seed tray and plug tray position. Stopping on specific degree was achieved by attaching mechanical stopper to the table. Here rotary motion is done manually by the worker, about 2 seconds of time is taken to oscillate $100^{\circ}$. So to complete one cycle (seed stand-plug tray-seed stand) it takes 4 second.

\section{2) Nozzle Assembly}

Nozzle assembly contains of 3 sub-components. Bottom Plate, Side Frame and Top plate. Nozzles are attached with bottom plate, identical to plug tray. All components were supposed to make of Aluminum and to be joined by fasteners. Rubber seals can be used to make it leak proof. Here in the bottom plate internal threading will be done in order to fit nozzle. Various plug tray can be used for cultivation but according to local availability, one can choose plug tray matrix of $6 \times 12(72), 8 \times 13(104), 7 \times 14(98)$ and many more. And from the plug tray dimension, holes for nozzle can be determined. Here $6 \times 12(72)$ is used.

\section{3) Vibrating Seed Tray}

Seed tray was designed in such a way that nozzle assembly can easily pick up seeds from slots. It has slots of $15 \mathrm{~mm}$ depth, according to plug tray which is used for cultivation process. It is made of Aluminum to make it less weight. Seed Tray was kept $60 \mathrm{~mm}$ higher from table surface so vibrating motor can be fitted easily. Here $12 \mathrm{~V}$ D.C. unbalanced motor was used for vibrating. For optimal performance frequency can be set by adjusting the motor speed from the control unit.

\section{4) Pickup and Dropping system}

Here for picking and dropping the pneumatic system was used. Here a vacuum pump was used for sucking and dropping. Which creates vacuum at nozzle tip, the seed gets stuck at the tip then after whole nozzle assembly is moved to plug tray, where air flow is diverted and dropping operation is done. It is done with a solenoid valve. Air Pipes are used for connecting nozzle assembly and pump. Here pressure regulating valve and seed pickup height of nozzle can be adjusted to optimize seed singulation and efficiency.
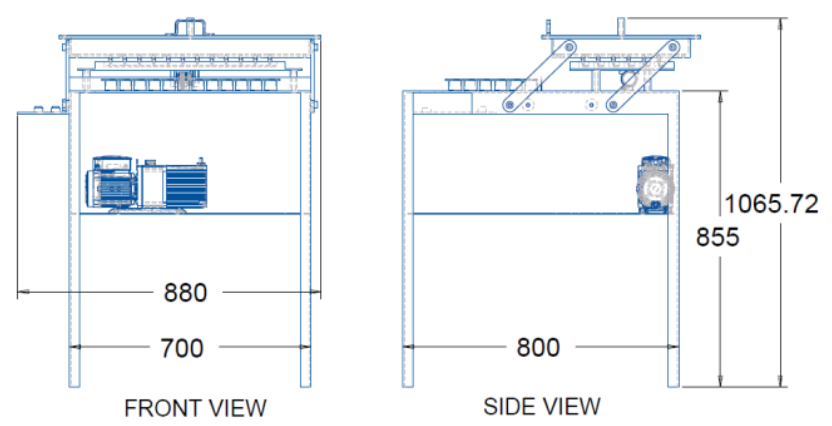

Fig. 1.Overall Dimension of Machine

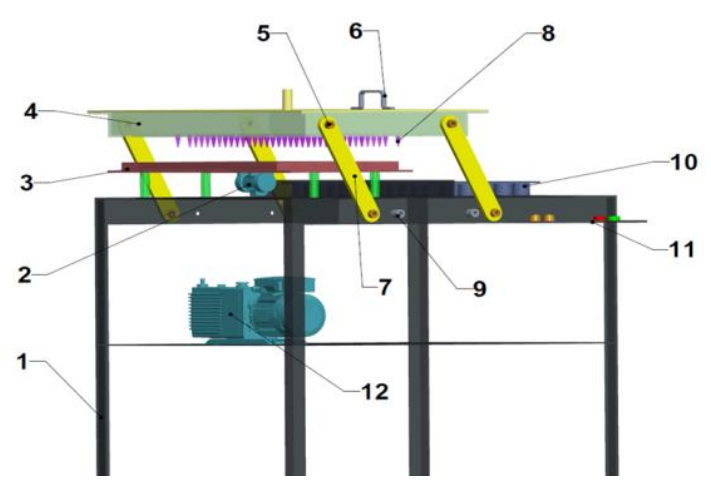

Fig. 2.Design of Machine

Table- I: Description of above figure

\begin{tabular}{|l|l|}
\hline Component No. & \multicolumn{1}{c|}{ Description } \\
\hline 1 & TABLE \\
\hline 2 & VIBRATING MOTOR \\
\hline 3 & SEED TRAY \\
\hline 4 & NOZZLE ASSEMBLY \\
\hline 5 & BRONZE BUSH \\
\hline 6 & HANDLE \\
\hline 7 & LINK \\
\hline 8 & NOZZLE \\
\hline 9 & STOPPER \\
\hline 10 & PLUG TRAY \\
\hline 11 & CONTROL UNIT \\
\hline 12 & VACUUM PUMP \\
\hline
\end{tabular}

Published By:

Blue Eyes Intelligence Engineering 


\section{Design of Major Components}

\section{1) Design of Link}

Link is the most important part of the machine it has to withstand the weight of nozzle assembly and have to move it from one place to another.

It will be in constant movement so it is essential to design it properly on the base of calculation.

\section{Bending stress at rest}

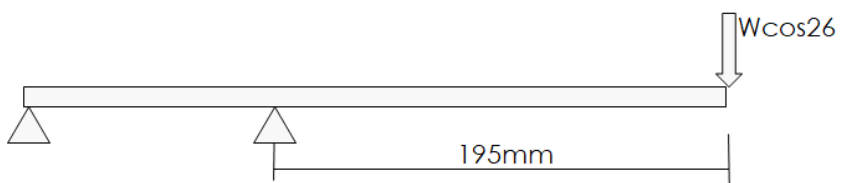

Fig. 3.Bending moment diagram of link

Weight $\mathrm{w}=2.70 \times 9.81 \times \cos 26=24.26 \mathrm{~N}$, Distance $\mathrm{l}=195 \mathrm{~mm}$ Moment $=24.26 \times 195=4732.15 \mathrm{Nmm}$

Moment of inertia I = $53333.33 \mathrm{~mm} 4$

Bending stress $=\mathrm{MY} / \mathrm{I}=1.77 \mathrm{MPa}$

Bending strength of material $=124 \mathrm{MPa}$

Hence design is safe against bending failure.

\section{Buckling Failure}

Here, length of link is $240 \mathrm{~mm}$ and minimum dimension is thickness which is $10 \mathrm{~mm}$. As (Effective Length)/(Least Column Dimension) $>12$ it is long column so formula of Euler's can be applied.

Maximum load acting on link Pcr $=2.70 \times 9.81$

$$
=26.5 \mathrm{~N}
$$

Equation of Maximum Axial loading is

$$
\frac{\pi^{2} E I}{(K L)^{2}}
$$

$\mathrm{E}=$ Modulus of Elasticity $=69 \mathrm{GPa}$

$\mathrm{L}=$ Length between center $=240 \mathrm{~mm}$

$\mathrm{K}=$ End fixity coefficient $=0.5$ (Fixed at both ends)

$\mathrm{I}=$ Moment of Inertia $=3333.33 \mathrm{~mm} 4$

Putting values into equation (1),

Maximum Axial loading $=80 \mathrm{KN}$

Maximum Axial loading $>$ max load on link

Hence, the design is safe against buckling failure.

\section{2) Design of Brass Bush}

Here the bush is required because of continuous motion, repeatedly after wear, it can be replaced so the farmer can save the cost of link wear. Also by using such material we can reduce friction which will reduce wear.

Life cycle of bush

Specific bearing load $=F d \times l$

$$
=0.135 \mathrm{MPa}
$$

Sliding speed oscillation $(\mathrm{v})=(\pi \times \mathrm{d} \times \theta \times \mathrm{N}) / 21600000$

$$
\begin{aligned}
\text { Life Cycle } & =\frac{K a}{\left(p \times v^{1.2}\right)} \times f c \times f d \times f p \times f m \\
& =14.85 \times 10^{6} \text { cycle }
\end{aligned}
$$

3) Contact Stress between Link and Bush

Link and bush will be in continuous relative motion so it is necessary to find out contact stress.

Table- II: Parameter of components and stress results generated from it.

\begin{tabular}{|c|l|l|}
\hline \multirow{2}{*}{ Parameter } & \multicolumn{2}{|c|}{ Components } \\
\cline { 2 - 3 } & Brass Bush & $\begin{array}{l}\text { Aluminum } \\
\text { Link }\end{array}$ \\
\hline Poisson's ratio & 0.331 & 0.33 \\
\hline
\end{tabular}

\begin{tabular}{|c|l|l|}
\hline \multirow{2}{*}{ Parameter } & \multicolumn{2}{|c|}{ Components } \\
\cline { 2 - 3 } & Brass Bush & $\begin{array}{l}\text { Aluminum } \\
\text { Link }\end{array}$ \\
\hline Modulus of Elasticity & $97 \mathrm{GPa}$ & $69 \mathrm{GPa}$ \\
\hline Diameter & $19.9 \mathrm{~mm}$ & $20.1 \mathrm{~mm}$ \\
\hline $\begin{array}{c}\text { Maximum Hertzian Contact } \\
\text { Pressure }\end{array}$ & $65.9 \mathrm{MPa}$ & $65.9 \mathrm{MPa}$ \\
\hline $\begin{array}{c}\text { Max. Shear Stress } \\
\text { Depth of maximum Shear } \\
\text { Stress }\end{array}$ & $19.6 \mathrm{MPa}$ & $19.6 \mathrm{MPa}$ \\
\hline
\end{tabular}

As maximum contact pressure and Max shear stress is less than material strength, so it is safe.

4) Static Analysis of Table

It was hard to find out stress on the table because every components has a downward force of its own weight. So at various place forces are acting so it was faster and easier to do it with static analysis on ANSYS 19.2 software. Here table was modelled into PTC CREO 4.0 and it was imported into ANSYS. Static Structural analysis optioned was used based on mechanics, $4 \mathrm{~mm}$ size of mesh was taken as optimum. Here displacement constraint was given at the base of the table and force of corresponding components was applied as a force vector.

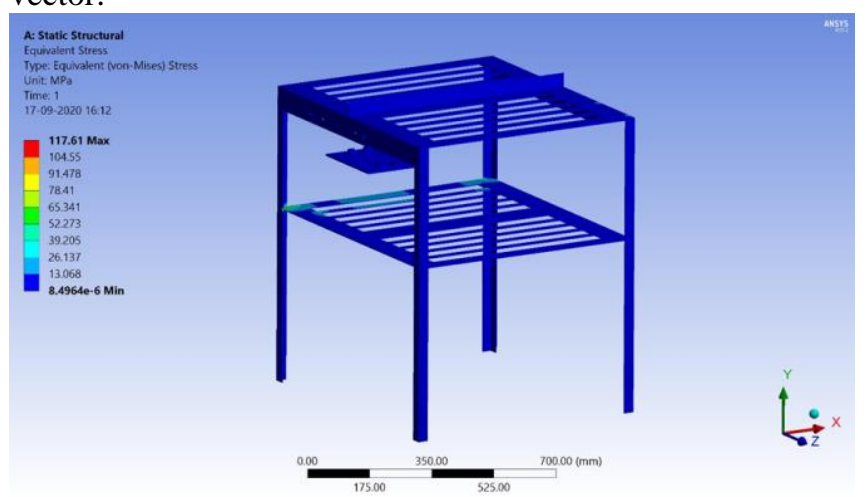

Fig. 4.Analysis of table

From the figure, maximum (von-mises) stress was of around 117.61MPa. So by considering material strength of Structural Steel, factory of safety was around 2.1 which is appropriate.

\section{COST ESTIMATION}

Table- III: Table of the cost of the machine which is estimated from one of the quotation.

\begin{tabular}{|l|l|l|l|l|}
\hline Sr. No. & Description & Quantity & Rate(₹) & Cost(₹) \\
\hline 1 & Nozzle Assembly & 1 & 5000 & 5000 \\
\hline 2 & Link & 4 & 400 & 1600 \\
\hline 3 & Seed Stand & 1 & 2000 & 2000 \\
\hline 4 & Base Frame & 1 & 1500 & 1500 \\
\hline 5 & Nozzle & 72 & 10 & 720 \\
\hline 6 & Bush & 8 & 50 & 400 \\
\hline 7 & Suction Pump & 1 & 6000 & 6000 \\
\hline 8 & Miscellaneous & 1 & 500 & 500 \\
\hline & TOTAL & & & 17720 \\
\hline
\end{tabular}

In market some companies has built precision seeder but it is noticed that they are so much costly, some are because of being fully automatic and some are because of complexity.

Published By:

Blue Eyes Intelligence Engineering and Sciences Publication 


\section{Design and Development of Chilli Seeder}

\section{CONCLUSION}

1. The study attempted to design a cheaper and accurate chilli seeder machine and it is almost achieved. It is important to fabricate locally in order to make in cheaper.

2. The design can give a seedling rate of approximately 32,400 seeds per hour with $6 \times 12$ (72) plug tray, seedling rate can even be maximized to 46,800 seeds per hour by choosing $8 \times 13(104)$.

3. In future with smaller modification and by changing nozzle diameter and suction pressure machine can be used for another type of seed also.

\section{REFERENCES}

1. Chen J M; Yu C C; Lei J H; Yu J M; Chang C F (1993). A multipurpose vacuum seed planter for vegetable crops plantings. Journal of Agriculture and Forestry, 42(1), 1-18

2. Kim D E; Chang Y S; Kim S H; Lee G I (2003). Development of vacuum nozzle seeder for cucurbitaceous seeds (I) - design factors for vacuum seeding large sized seeds. Journal of the Korean Society for Agricultural Machinery, 28(6), 525-530

3. Hu J; Hou J; Mao H (2003). Development and test of magnetic precision seeder for plug seedlings. Transactions of Chinese Society of Agricultural Engineering, 19(6), 122-125

4. B.B.Gaikwad, N.P.S. Sirohi (2007). Design of a low-cost pneumatic seeder for nursery plug trays. Biosystems Engineering 99(3):322-329

5. Tarek H. A. Mohamed*; Hossam M. T. EL-Ghobashy;* Adel A. M. EL-Ashker *; Ahmed R.Hamed* (2017). An innovating precision sowing unit for tray nursery. Misr Journal of Agricultural Engineering 34(2), 725-750

6. D.A. Naik, H.M. Thakur (2017). Design and analysis of an automated seeder for small scale sowing applications for tray plantation method. International Journal of Engineering Research and Technology, Volume 10, Number 1.

\section{AUTHORS PROFILE}

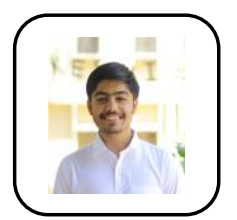

Digvijaysinh B Dodiya, Done B.Tech in 2020 from Mechanical Engineering Department at BVM Engineering College, V.V.Nagar, Anand (Gujarat), India.

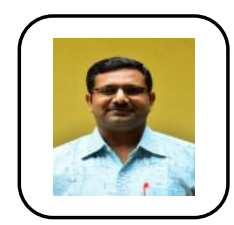

1. Prof. Jayesh R Koisha, Working as an Assistant Professor in Mechanical Engineering Department at BVM Engineering College, V.V.Nagar, Anand (Gujarat), India. Email: jrkoisha@bvmengineering.ac.in. 